\title{
Alguns aspectos da reforma da inteligência na América Latina*
}

\author{
Some aspects of reforming intelligence in Latin America ** \\ PETER GILL \\ Universidade de Liverpool, Reino Unido \\ Roxby Building, Liverpool, L697ZT, UK \\ P.Gill@liverpool.ac.uk
}

RESUMO Este artigo identifica algumas das características principais da reforma no setor de inteligência na América Latina, dentro do contexto mais amplo das relações entre os estados e os agentes de segurança. São consideradas três questões principais: o legado autoritário, a transição e o lugar em que os estados se encontram, mas esta última questão é abordada mais para a conveniência da análise do que para sugerir qualquer sequência natural e necessária ou um destino para a mudança. Exemplos tirados da reforma das agências estatais de inteligência na Argentina e no Brasil são discutidos dentro da ideia mais ampla de "securitismo": um conceito amplo que descreve como o setor de segurança é governado atualmente em termos de interpenetração e dependência mútua dos estados, empresas e agentes "comunitários".

Palavras-chave inteligência, governança, segurança.

ABSTRACT This article identifies some of the main features of intelligence sector reform in Latin America within the broader context of the relationships between states and other security actors. Three main questions are considered: the authoritarian legacy, the transition and where states are now, but this is for convenience of analysis rather than implying any necessary sequence of or destination for change. Examples drawn from the reform of state intelligence agencies in Argentina and Brazil are discussed within

* Artigo recebido em: 10/02/2012. Autor convidado.

* O autor agradece a The Leverhulme Trust, cuja concessão de uma Emeritus Fellowship facilitou a pesquisa que resultou neste artigo. 
the broader idea of "securitism": an umbrella concept describing how the security sector is currently governed in terms of the inter-penetration and mutual dependence of state, corporate and 'community' actors.

Keywords intelligence, governance, security.

\section{Introdução: analisando a democratização}

O processo histórico de democratização é caracterizado geralmente como tendo ocorrido em "ondas", sendo o da América Latina parte integrante da terceira onda ${ }^{1}$ de Samuel Huntington (pós-1974); mas não é necessário dizer que isso pode esconder muitas variações. John Peeler examinou os processos ocorridos na América Latina de forma mais especifica e percebeu a ocorrência de duas vastas "ondas", a primeira ocorrida entre as décadas de 1920 e 1960 (coincidindo com a segunda de Huntington) e a segunda iniciando-se em 1970, com o estabelecimento de "regimes formalmente democráticos" na maioria dos países da região. ${ }^{2}$ Houve, no entanto, algumas significativas "des-democratizações" como no Chile e no Uruguai em 1973. Mais recentemente, a durabilidade das democracias na América Latina na primeira década do século XXI, apesar de algumas crises econômicas graves, levou alguns estudiosos a mudarem o foco de sua análise das transições e da consolidação para considerarem a qualidade das democracias. ${ }^{3}$ A discussão aqui é estruturada em torno de três questões principais: o legado autoritário, a transição e onde os estados se encontram - mas esta última ocorre apenas para a conveniência de análise e não implica qualquer padrão pré-estabelecido para a democratização. A democracia pode emergir em fragmentos sem nenhuma sequência fixa ${ }^{4}$ e há muita "incerteza" em todo o processo. ${ }^{5}$ Na verdade, o processo pode ir em marcha à ré ${ }^{6}$ e essa possibilidade tende a aumentar na medida em que os governos, mais preocupados com a segurança do que com a democracia, procuram restringir o entusiasmo precoce que emerge logo após a queda dos regimes autoritários.

Este artigo identifica algumas das características principais da mudança no setor de inteligência de segurança na América Latina dentro do contexto mais amplo das relações entre os estados e os outros agentes de segurança. Especificamente, preocupa-se com a inteligência de segurança interna/doméstica e não com a inteligência militar em si. Claramente, não

1 HUNTINGTON, Samuel P. The third wave: democratization in the late twentieth century. Norman: University of Oklahoma Press, 1991.

2 PEELER, John. Building democracy in Latin America. 2.ed. London: Lynne Rienner, 2004, p.43.

3 LEVINE, Daniel e MOLINA, José. The quality of democracy in Latin America. Boulder: Lynne Rienner, 2011, p.1.

4 DIAMOND, Larry. Developing democracy: towards consolidation. Baltimore: John Hopkins University Press, 1999, p.16 e cf. CAROTHERS, Thomas. The "sequencing" fallacy. Journal of Democracy, v.18, n.1, p.12-27, January 2007.

5 O'DONNELL, Guillermo e SCHMITTER, Philipp C. Transitions from authoritarian rule: tentative conclusions about uncertain democracies. Baltimore: Johns Hopkins University Press, 1986.

6 TILLY, Charles. Democracy. Cambridge: CUP, 2007, p.51-79. 
há generalizações que podem ser aplicadas da mesma forma, no todo, em uma região tão grande e diversificada, mas espera-se que esta análise, que inclui exemplos específicos principalmente da Argentina e do Brasil, provoque a reflexão e a análise mais aprofundada da democratização dos serviços de inteligência em outros países. ${ }^{7}$

\section{Democratizando os serviços de Inteligência}

A literatura em relação à democratização do setor de segurança tem se preocupado, principalmente, com a reforma militar e das polícias, e quase nada com os serviços de inteligência. Isso é tão verdadeiro para a América Latina, quanto é para a Europa. ${ }^{8} \mathrm{~A}$ falta de dados agregados que sejam relevantes significa que a democratização da inteligência não pode ser analisada da mesma maneira quantitativa como o trabalho na administração pública e na política, embora os conceitos fundamentais, tais como responsabilidade e autonomia, permaneçam essenciais.

Há dois quadros principais em que a democratização da inteligência é discutida: primeiro, no das relações civis-militares, desenvolvido principalmente em relação à América Latina. Por exemplo, Tom Bruneau e Cris Matei referem-se à necessidade de controle civil da inteligência, incluindo a supervisão e o desenvolvimento de normas profissionais. ${ }^{9}$ Dado que o autoritarismo na América Latina foi principalmente de caráter militar (o México foi uma exceção notável), essa abordagem é compreensível, mas a segunda abordagem - da reforma do setor de segurança - é preferida aqui, baseado no fato de que o controle civil é uma condição necessária, mas não suficiente para a democratização, pois "é perfeitamente possível ter o controle civil dos militares que seja não-democrático, anti-democrático ou mesmo militarista". ${ }^{10} \mathrm{~A}$ vantagem da análise de inteligência como parte de uma ampla reforma do setor de segurança é que a inteligência de segurança irá tanto influenciar quanto será influenciada por transformações ocorridas entre os militares, os policiais e outros agentes de segurança.

A literatura até o momento, abordando tanto as relações civis-militares quanto a reforma do setor de segurança, enfatiza as questões históricas e institucionais. Isso não é surpreendente, considerando a estreita relação da inteligência com o poder do estado, mas é importante reconhecer o contexto

7 Como, por exemplo, em ESTÉVEZ, Eduardo. Comparing intelligence democratization in Latin America: Argentina, Peru, and Ecuador Cases. (no prelo)

8 BORN, Hans e LEIGH, lan. Making intelligence accountable: legal standards and best practice for oversight of intelligence agencies. Oslo: Publishing House of Parliament of Norway, 2005; BORN, Hans, JOHNSON, Loch e LEIGH, lan. (eds.) Who's watching the spies: establishing intelligence service accountability. Washington DC: Potomac Books Inc, 2005; BRUNEAU, Thomas C. e BORAZ, Steven. Reforming intelligence: obstacles to democratic control and effectiveness. Austin: University of Texas Press, 2007, são das principais exceções.

9 BRUNEAU, Thomas C. e MATEI, Cris. Towards a new conceptualization of democratization and civil-military relations. Democratization, v.15, n.5, p.909-929, 2008.

10 CAWTHRA, Gavin e LUCKHAM, Robin. Democratic control and the security sector. In: CAWTHRA, G. e LUCKHAM, R. (eds.) Governing insecurity: democratic control of military and security establishments in transitional democracies. London: Zed Books, 2003, p.305. 
social, político e econômico de forma mais ampla. Por exemplo, um aspecto importante da democratização, tanto na América Latina quanto na Europa, tem sido o contexto do neoliberalismo que fez com que os estados estivessem, muitas vezes, buscando não apenas democratizar o sistema político, mas também "marquetisar" a economia. Thomas Carothers, por exemplo, discutiu a necessidade de promotores da democracia e de trabalhadores humanitários para analisar a privatização e seu impacto. ${ }^{11}$ Como veremos, isso nos alerta para o papel dos atores de inteligência não-governamentais e seu lugar dentro das redes de segurança e de inteligência.

Outra questão é se, mesmo nos estados nos quais a democracia pode parecer "consolidada", a natureza distinta da inteligência como uma atividade exige uma forma mais limitada da democracia ou de "democraduras"; estados nos quais certas questões permanecem fora da agenda política e restrições continuam a recair sobre certas liberdades políticas. ${ }^{12}$ Essa possibilidade pode ter sido reforçada no 11 de setembro, quando passaram a ocorrer pressões consideráveis para se abandonar as conquistas democráticas dos últimos trinta anos a partir da crença ingênua de que agências "desimpedidas" de requisitos de supervisão podem, assim, ser mais eficientes e eficazes.

\section{Legado da autoridade}

A centralidade das agências de segurança e inteligência nos regimes autoritários é clara: "Em países como Chile, Peru, Guatemala e Brasil (pelo menos até 1989), presidentes eleitos ou nomeados têm sido fortemente influenciados por seus conselheiros de inteligência". ${ }^{13}$ De certa maneira, o papel da inteligência em regimes autoritários na América Latina foi equivalente a dos "estados de contra-inteligência" no Bloco de Varsóvia. ${ }^{14}$ Por exemplo, a doutrina de segurança nacional na América Latina uniu inteligência interna, externa e contra-inteligência ${ }^{15}$ e dependeu de uma noção de "inimigos internos", que incluiria esquerdistas independentes, liberais, sindicalistas independentes, ativistas pela paz, etc. O primeiro serviço de inteligência civil foi criado no Brasil em 1958, mas mudou para o Serviço Nacional de Informações (SNI), após os militares tomarem o poder em 1964. O SNI permaneceu formalmente civil, mas tornou-se militarizado através de preenchimento de muitos postos-chave por oficiais de patente. Estabeleceu

11 CAROTHERS, Thomas. The end of the transition paradigm. Journal of Democracy, v.13, n.1, p.5-21, 2002.

12 O'DONNELL, G. e SCHMITTER, P. Transitions from authoritarian rule, p.9.

13 KOONINGS, Kees. Political armies, security forces and democratic consolidation in Latin America. In: CAWTHRA, G. e LUCKHAM, R. (eds.) Governing insecurity, p.131.

14 DZIAK, John. Chekisty: a history of the KGB. Lexington MA: Lexington Books, 1988

15 UGARTE, José Manuel. Latinoamérica: legislación y políticas relativas a la actividad de inteligencia. Evolución y realidad actual. In: CHAMORRO, Laura. (ed.) Sistemas de inteligencia comparados: aportes al caso peruano. Lima: Instituto de Estudios Políticos y Estratégicos (IDEPE), 2010. Traduzido por Mike Edwards; ESTÉVEZ, Eduardo, E. Argentina's intelligence in the twenty-first century / after twenty-five years of democracy. In: ISA, Paper... p.13-14, february 2010. 
diretórios junto aos ministérios e nas universidades e "tornou-se um quarto serviço militar, ou mesmo um estado dentro do estado, com estrutura e poderes que poderiam ser comparados com os dos serviços secretos dos regimes comunistas, como a KGB soviética". ${ }^{16}$ Este se originou das teorias leninistas - deve-se notar que a National Security Doctrine Regimes (NASEDO) na América Latina também se baseou fortemente na doutrina militar dos EUA, o que ocorreu inicialmente no Brasil. ${ }^{17}$ Uma diferença significativa em relação à Europa, porém, é que não havia equivalente na América Latina de subordinação eficaz da segurança interna e das agências de inteligência como ocorria em relação com a KGB soviética. No entanto, a Romênia e a lugoslávia foram exceções à regra e, da mesma forma, é necessário ter em mente as diferenças existentes entre os diversos regimes militares. Por exemplo, Estevez distingue os militares relativamente "progressistas" do Peru e do Equador do regime argentino "neoliberal". ${ }^{18}$

Legados malignos são encontrados em todas as estruturas e processos de "inteligência da segurança": a falta de qualquer base jurídica clara para o mandato ou a distribuição do orçamento; a falta de profissionalismo, incluindo a pobre capacidade analítica; o recrutamento por razões ideológicas e não por mérito; a falta de gestão e a permanência de tecnologias desatualizadas. Isso também caracterizava as agências na Europa mas, na América Latina, o governo não estava sujeito à mesma disciplina do partido, o que na Europa significou, em grande parte, que essas estruturas do estado não se transformaram em organizações "paralelas" ou esquadrões da morte, como ocorreu na América Latina. ${ }^{19} \mathrm{~A}$ pior consequência foi o abuso frequente dos direitos humanos, tanto em relação à coleta de informações, quanto no que diz respeito as ações para eliminar a oposição. A Secretaría de Inteligencia de Estado (SIDE) na Argentina envolveu-se fortemente em abusos, incluindo assassinatos entre os anos 1976 e 1983, e a reforma no Brasil teve que lidar com "o estigma nocivo associado às organizações de inteligência durante a ditadura militar de 1964 a 1985".20

Por ordem dos EUA, desde o 11 de setembro, durante a última década, tem sido dada grande ênfase à necessidade de cooperação dos serviços de inteligência entre os diversos países da América Latina. Apesar da cooperação transnacional não ser uma novidade, a história dessa cooperação pode ter soado como um alerta para os potenciais abusos dessa "cooperação", como manifesto de uma extraordinária rendição. A Operação Condor foi criada em 1973-74 como uma rede de cooperação secreta por meio da qual

16 Alfred Stepan citado em: GONÇALVES, Joanisval Brito. The spies who came from the tropics: intelligence services and democracy in Brazil. (no prelo)

17 TAPIA-VALDÉS, Jorge A. A typology of national security policies. Yale Journal of World Public Order, v.9, n. 10, p.1039, 1982.

18 ESTÉVEZ, E. Comparing intelligence democratization in Latin America.

19 Mas isto ocorreu em partes da Europa com o fim do comunismo, notavelmente na lugoslávia e Rússia.

20 CEPIK, Marco e BRUNEAU, Tom. Brazil. In: FARSON, Stuart et al. (eds.). PSI Handbook of global security intelligence: national approaches. Westport, CT.: Praeger Security International, 2008, v.l, p.112. 
os governos militares da Argentina, Peru, Chile, Bolívia, Paraguai, Uruguai e Brasil se envolveram na apreensão e no assassinato de opositores políticos além de suas fronteiras nacionais. ${ }^{21}$

\section{Transição}

Jean Grugel resume uma série de condições que melhoram as perspectivas de democratização ${ }^{22}$ e é útil considerar, embora brevemente, onde se situa a América Latina em relação a elas. Em primeiro lugar, o capitalismo deve ser o modo dominante de produção; esse é certamente o caso, embora o desenvolvimento da industrialização e da urbanização nas economias latino-americanas tenha sido mais tardio e fortemente influenciado pelos estados industriais mais avançados, como os EUA e a Europa Ocidental. Isso tem sido descrito como "desenvolvimento capitalista tardio e dependente". ${ }^{23}$ Em segundo lugar, grupos ativos da sociedade civil e politizados são obrigatórios. Esse é um problema para a reforma dos sistemas de inteligência em todos os lugares, por causa dos inteiramente bem justificados medos, sentidos por esses grupos ao expressarem ideias ou defenderem mudanças nos países até recentemente autoritários, embora a "sociedade civil" possa ser pouco visível nos assuntos de inteligência. No mais, esse "estigma nocivo" muitas vezes também afeta a disposição dos membros do legislativo de se envolverem nas reformas.

Em terceiro lugar, os conflitos de classe e outros conflitos sociais devem ser resolvidos através da incorporação ao sistema político. Graves e crescentes desigualdades econômicas e sociais na America Latina deixam claro que esses conflitos não foram resolvidos de maneira nenhuma, mas foram incorporados historicamente por meio do "corporativismo". Ao generalizar suas análises sobre os regimes militares dos anos 70, Malloy percebeu que o "ponto crítico de semelhança é que cada um destes regimes é caracterizado por estruturas governamentais fortes e relativamente autônomas que buscam impor à sociedade um sistema de representação de interesses baseado no pluralismo limitado e reforçado". ${ }^{24}$ Dada a centralidade da noção de pluralismo para o ideário da democracia liberal, pode-se supor que essa restrição teve que mudar a fim de facilitar algumas transições para a democracia, mas,

a expansão, no século XX, da participação política para além do estreito elitismo prevalecente nos anos 1900, para um conceito, à medida que avançamos no

21 ESTÉVEZ, Eduardo. Argentina's intelligence in the twenty-first century, p.15-16.

22 GRUGEL, Jean. Democratization: a critical introduction. Basingstoke: Palgrave, 2002, p.45; Cf. SøRENSEN, Georg. Democracy and democratization: processes and prospects in a changing world. Boulder, CO: Westview Press, 2008, p. 160

23 MALLOY, James. Authoritarianism and corporatism in Latin America: the modal pattern. In: MALLOY, J. (ed.). Authoritarianism and corporatism in Latin America. Pittsburgh: University of Pittsburgh Press, 1977, p.5-8.

24 MALLOY, J. Authoritarianism and corporatism in Latin America, p.4. 
século XXI, de cidadania virtualmente universal é visto muito mais em termos de incorporação de agentes coletivos identificáveis do que em termos de ampliação dos direitos dos indivíduos (...) apesar de que as Constituições da América Latina tenham assumido uma forma convencionalmente contratualista, seu significado mais profundo é melhor compreendido em termos do legalismo ibérico/romano e do corporativismo medieval. ${ }^{25}$

Voltaremos a isso mais a frente.

Em quarto lugar, é necessário um estado relativamente autônomo e não sob a dominação da elite e, em quinto lugar, ele precisa de recursos estatais suficientes para a redistribuição e aplicação da lei. Claramente, a autonomia dos estados, especialmente em relação às elites militares, aumentou, como será discutido abaixo. Mas pode ser sugerido que, até agora, a transição ocorreu apesar da ausência de recursos adequados para a redistribuição e aplicação da lei.

A sexta condição de Grugel é que a democracia seja promovida pela ordem internacional ou que o país exista dentro de uma "região democrática", onde agrupamentos melhoram as perspectivas para a democracia. ${ }^{26}$ Não há equivalente na América Latina da UE/NATO, mas a posição dos EUA como potência hegemônica regional é importante. Durante a Guerra Fria, seu interesse na região foi definido como oposição a quaisquer movimentos populares e governos com proximidade real ou imaginária do comunismo. Isso mudou, mas a promoção da democracia ainda é mediada por necessidades de segurança e, pelo menos, pela "marketisação" ${ }^{27}$ Michael Shifter observa um declínio da influência dos EUA na América Latina, resultado da sua atuação no Afeganistão, no Iraque e dos abusos dos direitos humanos associados à sua presença nesses países. Mas, em termos institucionais mais estreitos, Gonçalves observa a importância contínua dos modelos de inteligência e de governança da América do Norte - EUA e Canadá - para o Brasil. 28

A integração regional entre Argentina, Brasil e Chile também reduziu a influência do velho "modelo de guerra" do discurso de segurança nacional, e os países do MERCOSUL, além de outros, agora estão cada vez mais envolvidos em trocas de inteligência em relação ao terrorismo, tráfico de armas e outras questões de fronteiras. ${ }^{29}$ Da mesma forma, o envolvimento de militares de diferentes países latino-americanos em missões de paz mundiais

25 PEELER, J. Building democracy, p.35.

26 DORENSPLEET, Renske e KOPECKÝ, Petr. Against the odds: deviant cases of democratisation. Democratization, v.15, n.4, p.697-713, 2008.

27 GRUGEL, J. Democratization, p.46-51, 65 e 189.

28 SHIFTER, Michael. Emerging trends and determining factors in democratic governance. In: DOMINGUEZ, Jorge e SHIFTER, Michael. (eds.) Constructing democratic governance in Latin America. Baltimore: The Johns Hopkins University Press, 2008, p.3-10; GONÇALVES, J. B. The spies who came from the tropics: intelligence services and democracy in Brazil.

29 ANTUNES, Priscila. Argentina. In: FARSON, Stuart et al. (eds.) PSI Handbook of Global Security Intelligence: National Approaches, v.l, p. 95-111. 
teve um efeito democratizante por meio da formação compartilhada de seus agentes e da sua exposição à democracia e a questões do respeito à lei. ${ }^{30}$

Em relação à inteligência, especificamente, Estévez examina o caso da Argentina, do Peru e do Equador e observa períodos de relativa estabilidade em que ocorreram poucas mudanças, apoiando a ideia de "caminho dependente", mas observa também que esses países foram abalados por episódios de mudanças rápidas. Nesses momentos foram "bloqueados" qualquer recuo a situações pré-existentes, podendo ser descritos como "momentos críticos" na consolidação da democracia. ${ }^{31}$ Essa idéia parece contradizer o ponto anterior de que a redemocratização possa ocorrer em qualquer lugar, mas, ao longo do tempo, essa é uma questão que precisa ser submetida a um exame empírico. Os passos iniciais para se distanciar do regime autoritário podem assumir várias formas, por exemplo: Existe algum tipo de pacto com os membros da oposição, expectativa de recuo ou, mais dramaticamente, de golpe?32

Na Argentina, ou a inteligência militar não esteve envolvida na Junta que preparou invasão das Malvinas/Falklands, em 1982, ${ }^{33}$ ou falhou na correção dos equívocos encetados pelo regime nessa operação. ${ }^{34}$ De qualquer maneira, o regime militar sofreu uma perda total de legitimidade após a derrota para a Grã-Bretanha. A velocidade da queda, no entanto, não permitiu que os líderes civis exigissem uma transferência imediata do poder, o que fez com que os militares mantivessem alguma influência temporária, até que os resultados eleitorais pressagiaram uma transição mais rápida do que a que viria a ocorrer no Brasil, Chile ou Uruguai. As primeiras mudanças incluíram proibições aos oficiais que ocupassem cargos governamentais fora do âmbito militar e uma nova lei, de 1988, redefiniu o papel dos militares da segurança "nacional" (ou seja, interna) para a segurança externa. Uma Lei de Segurança Interna, de 1992, responsabilizou o Ministério do Interior pela segurança interna, criando uma Diretoria de Inteligência Interna para coordenar as atividades de inteligência da polícia e do SIDE, e estabeleceu uma comissão bicameral do congresso para supervisionar os serviços de inteligência. Debates posteriores, ocorridos na década de 90, acabaram resultando numa Lei de Inteligência, de 2001, aprovada em dezembro em meio a uma grave crise política e econômica. ${ }^{35}$

30 DIAMINT, Rut. Military, police, politics, and society; Does Latin America have a democratic model? In: DOMíNGUEZ, Jorge e JONES, Anthony. (eds.) The construction of democracy: lessons from practice and research. Baltimore: The Johns Hopkins Press, 2007, p.155.

31 ESTÉVEZ, E. Comparing intelligence democratization in Latin America.

32 MAINWARING, Scott. Transitions to democracy and democratic consolidation: theoretical and comparative issues. In: MAINWARING, S. et al. Issues in democratic consolidation: the new South American democracies in comparative perspective. Notre Dame: University of Notre Dame Press, 1992, p.294-341.

33 ANTUNES, P. Argentina, p.95.

34 CAVALLINI, Enrique H. J. The Malvinas/Falkland affair: a new look. International Journal of Intelligence and Counterlntelligence, v.2, n.2, p.209, 1988. Cit. ESTÉVEZ, E. Argentina's intelligence in the twenty-first century, p.17.

35 ANTUNES, P. Argentina, p.95-100; SILLONE, Jorge Osvaldo. El caleidoscopio del poder en la Argentina: su influencia en la inteligencia estratégica. In: SWENSON, Russell e LEMOZY, Susana (eds.). Democratización de la función 
No Brasil, os debates sobre uma nova constituição após o restabelecimento do governo civil em 1980 não abordaram explicitamente a questão dos sistemas de inteligência, mas em 1990 Collor de Mello extinguiu o SNI e o Sistema Nacional de Informações (SISNI) instituindo, então, um debate sobre o papel da inteligência. Uma Lei de 1999 criou um novo serviço de inteligência, a Agência Brasileira de Inteligência (ABIN), como uma agência civil, sem poderes de polícia, mas responsável pela segurança interna e inteligência externa, planejada para ser o órgão central do Sistema Brasileiro de Inteligência (Sisbin). ${ }^{36}$

\section{Onde estão agora? Estado atual da segurança e da inteligência na América Latina}

Interrogar toda uma gama de indicadores para discutir se os países da América Latina afinal consolidaram, pararam ou regrediram no avanço da democracia não ajudaria realmente a análise da governança sobre os sistemas de segurança. Alguns indicadores são relevantes. Por exemplo, foi implantada uma classificação de quatro pontos sobre o controle civil dos militares: a partir de 1. controle militar; 2. tutela militar; 3. subordinação condicional militar e 4. controle civil. Levine e Molina colocam a Argentina no patamar 4 (controle civil sobre militar em todas as áreas), o Brasil no 3 (militares não intervêm diretamente, mas têm poder de veto e o direito de intervir no que consideram ser o interesse nacional), enquanto Cepik e Bruneau localizam o Brasil entre 3 e $4 .{ }^{37}$ Existem outros indicadores em relação ao estado de direito, as incidências de violência civil, a corrupção e as liberdades civis que poderiam ser compilados como uma espécie de índices de segurança interna, mas não há espaço suficiente para fazer isso aqui.

Embora a redução da autonomia dos militares (e suas agências de inteligência a eles associadas) seja uma questão importante no contexto da América Latina, como sugerido na Introdução, isso nos descortina apenas uma parte da história. Mesmo em democracias bem estabelecidas, que se saem bem em medidas convencionais de poliarquia em geral, no campo da governança da segurança, o sigilo e a tecnologia combinam-se para criar condições para o surgimento do corporativismo. Aqui o estado assume o papel central no reconhecimento ou até mesmo na organização da representação de interesses, em vez do "jogo livre de interesses", que é central para poliarquia. Por exemplo,

de inteligencia: el nexo de la cultura nacional y la inteligencia estratégica. Washington DC: NDIC, 2009, p.19-44. Traduzido por Sally Evans.

36 GONÇALVES, J. B. The spies who came from the tropics, p.5-7.

37 CEPIK, Marco e BRUNEAU, Tom. Brazil; e LEVINE, D. e MOLINA, J. Measuring the quality of democracy. In: LEVINE, D. e MOLINA, J. (eds.) The quality of democracy in Latin America. Boulder: Lynne Rienner, 2011, p.21-38. 
um sistema de representação de interesses é definido como corporativo na medida em que é caracterizado por um padrão em que o estado estrutura a representação, que produz um sistema de sansão oficial; associações de interesse não competitivas, que são organizadas em agrupamentos funcionais legalmente prescritos, na medida em que estas associações são subsidiadas pelo estado e na medida em que não há controle estatal explícito sobre as lideranças, a tomada de decisões e a governança interna dessas associações. ${ }^{38}$

Na literatura geral, o corporativismo institui-se de várias formas. Por exemplo, Schmitter distinguiu o corporativismo estatal, em que os interesses corporativos derivam a sua legitimidade a partir do estado, do corporativismo societal, no qual ele se institui de forma independente. ${ }^{39}$ Observando o período autoritário na América Latina, Guillermo O'Donnell diferenciou a exclusão política e o controle de grupos de classes mais baixos das interpenetrações mais complexas entre o estado e as classes dominantes e os setores econômicos que inventaram seu modelo de estado "burocrático autoritário". 40

Agora, a preocupação neste artigo não é procurar ressuscitar o conceito de corporativismo a fim de caracterizar a governança da América Latina como um todo (macrocorporativista), mas sugerir que pode ser uma maneira útil de ver o setor de segurança, cada vez maior e crescente, que não pode ser analisado de forma adequada como uma "poliarquia". Quais são as principais características do que poderíamos chamar de "securitismo"? ${ }^{41}$ Primeiro, o consenso ideológico no que diz respeito à segurança nacional e aos meios de luta contra o terrorismo reflete uma identidade entre as autocentradas e lucrativas corporações de segurança e seu apoio em relação às demais políticas do estado de segurança nacional. Portanto, as corporações de segurança não têm que fazer lobby junto aos governos a fim de influenciar suas políticas; as políticas já estão colocadas, a única questão é como devem ser implementadas. No caso da inteligência, isso tem sido visto mais claramente desde o 11 de setembro nos EUA. Logo após o atentado terrorista às Torres Gêmeas, o Comitê Seleto de Inteligência do Senado norte-americano pediu uma "relação simbiótica entre a Comunidade de Inteligência e o setor privado", ${ }^{42}$ e uma ideologia do Complexo de

38 COLLIER, David e COLLIER, Ruth. Who does what to whom, and how: towards a comparative analysis of Latin American Corporatism. In: MALLOY, J. (ed.) Authoritarianism and corporatism in Latin America, p.493.

39 Citado em COLLIER, D. e COLLIER, R. Who does what to whom, and how, p.495.

40 Por exemplo: O'DONNELL, Guillermo. Corporatism and the question of the state. In: MALLOY, J. (ed.) Authoritarianism and corporatism in Latin America, p.47-88.

41 Essa é uma versão do "meso-corporativismo". Ver: CAWSON, Alan. Corporatism and political theory. Oxford: Blackwell, 1986, p.39. Quanto mais essas características se espalham em outras áreas de policiamento, mais somos autorizados a falar de alguma forma de segurança nacional de estado, (Cf: TAPIA-VALDÉS, Jorge A. A typology of national security policies) mas esse assunto vai além do espectro deste artigo.

42 CHESTERMAN, Simon. We can't spy...If we can't buy!: the privatization of intelligence and the limits of outsourcing "inherently governmental functions". European Journal of International Law, v.19, n.5, p.1055-74, 2008. 
Inteligência-Industrial nasceu de uma mistura de "patriotismo, chauvinismo nacional, medo do desconhecido e lucro com a guerra à moda antiga". ${ }^{43}$

Segundo, há uma quase total interdependência mútua entre corporações de segurança e os estados modernos: o estado conta com o setor coorporativo para os serviços de infraestrutura, consultoria, software e hardware. Em troca, as corporações são dependentes do estado em relação aos contratos e ao quadro legal dentro do qual trabalham. Em alguns países, essa interdependência se aprofunda ainda mais pelo envolvimento direto dos militares na produção industrial, por exemplo, no Brasil, onde os militares controlam fabricantes de aeronaves, mísseis e automóveis blindados. ${ }^{44}$ Uma confluência da crise fiscal dos estados, da privatização, da competência tecnológica e da dependência para inovações no setor privado significa que a governança de segurança só pode ter lugar por meio de corporações privadas.

Terceiro, há um setor de segurança e inteligência não estatal, não corporativo, envolvendo muitos e variados grupos de cidadãos. Agora, alguns desses podem agir como "interesses organizados" que estão incorporados de alguma forma na governança de segurança, mas seu significado potencial vai muito além das estruturas normais do corporativismo, como veremos a seguir. Vamos examinar em linhas gerais os três principais constituintes - estado, corporação e comunidade/soberania de governança de segurança contemporânea na América Latina - antes de considerar as implicações de sua interpenetração nas redes de segurança e de inteligência que constituem o "securitismo".

\section{As agências estatais}

Dada a obsessão com os "inimigos internos", que caracteriza o autoritarismo, um passo precoce necessário para as democracias é desenvolver uma "doutrina" de segurança moderna que identifique ameaças à segurança nacional de forma mais objetiva do que simplesmente como opositores do governo. Há, então, questões subsidiárias, tais como o número de agências de inteligência que deve haver (ou, que podem ser pagas) e como suas análises e atividades podem ser coordenadas. O estabelecimento de um controle democrático exige uma definição clara do papel dos dirigentes eleitos na definição das missões das agências e no estabelecimento de procedimentos para a autorização de operações internas. Questões de recrutamento e treinamento têm de ser abordadas, incluindo a questão controversa da purificação dos quadros: como os responsáveis por abusos

43 SHORROCK, Tim. Spies for hire: the secret world of intelligence outsourcing. New York: Simon \& Schuster, 2008 p.357. Essa simbiose foi particularmente pronunciada nos EUA desde o 9 de setembro, mas há evidências desse desenvolvimento em outros lugares, por exemplo, ver AVANT Deborah. The market for force: the consequences of privatizing security. Cambridge: Cambridge UP, 2005.

44 PEELER, J. Building democracy, p.102. 
de direitos humanos anteriores serão impedidos de trabalhar em agências reformadas? Além disso, se eles forem removidos dos empregos estatais, serão pagas pensões adequadas para que eles não sejam tentados a vender suas habilidades para as organizações criminosas, reconhecendo que muitos ex-oficiais provavelmente migrarão para o sector de segurança privada?

A outra questão central para a reforma é o estabelecimento de sistemas de supervisão que requerem quatro níveis principais: os internos à agência, os ministeriais ou executivos, o parlamentar/judicial e os da mídia e da sociedade civil. Em países da América Latina, em geral, os mecanismos de fiscalização são apenas parlamentares e judiciais no que diz respeito à invasão de privacidade. Há uma ausência significativa de controle sobre as atividades de inteligência localizadas dentro do próprio poder executivo. ${ }^{45}$ Isso é importante porque, se o controle e a fiscalização são vistos por oficiais da inteligência como "forasteiros intrusos", pode haver pouca ou nenhuma mudança nas culturas organizacionais das agências e o objetivo da fiscalização - a prestação de inteligência mais eficiente, eficaz e adequada - é improvável de ser alcançado.

Enquanto alguns países, como, por exemplo, o Chile e o Peru, realizaram uma reestruturação de suas agências de inteligência mais radical, os sistemas anteriores de inteligência na Argentina e no México não foram apenas mantidos, mas aumentaram seus poderes significativamente como consequências da reestruturação. Na maioria dos países, a inteligência de segurança interna foi retirada do âmbito dos militares, mas em alguns Equador, Nicarágua e Honduras - os militares ainda são a principal força de segurança interna. ${ }^{46}$

O debate sobre uma nova doutrina de inteligência de segurança na Argentina durante a década de 1990 esteve intimamente ligado à influência relativa de agências militares e civis. Após o fim da Guerra Fria, a inteligência militar na Argentina procurou manter sua influência se reorientando para as novas ameaças assimétricas oriundas do tráfico de drogas, da migração e do terrorismo. A sociedade civil, ansiosa por evitar o envolvimento contínuo da inteligência militar na política de policiamento de "ameaças internas", finalmente conseguiu limitar o papel dos militares, desenvolvendo o conceito de "inteligência criminal" para enfatizar o contraste entre a inteligência estratégica e a militar. ${ }^{47}$ De forma semelhante, no Brasil, onde houve pouca apreensão em relação a ameaças externas à segurança nacional, a ênfase dada ao desenvolvimento de novas estruturas de inteligência recaiu sobre

45 UGARTE, José Manuel. Latinoamérica, p.2

46 UGARTE, José Manuel. Latinoamérica, p.5-6.

47 ANTUNES, P. Argentina, p.100-102; ESTÉVEZ, E. Argentina's intelligence in the twenty-first century, p.25-36. É claro, a ameaça não desaparece sem controle efetivo da "polícia política" e pode continuar sob o disfarce de "inteligência criminal". 
as ameaças relativas ao controle das fronteiras, dos índices de homicídios e do crime organizado. ${ }^{48}$

A Lei de Inteligência Nacional de 2001, na Argentina, substituiu o SIDE pela Secretaria de Inteligencia (SI) e incluiu disposições sobre o mandato nos serviços de inteligência, os direitos individuais, a coordenação de atividades de inteligência, a classificação das informações, as escutas telefônicas (após um longo debate foi combinado que seria necessária autorização judicial), o recrutamento e o controle parlamentar especialmente sobre o orçamento. ${ }^{49}$ Mas, como em outros lugares, a reestruturação legal não necessariamente reflete uma mudança real e cultural: "desde 1984, a liderança política ainda sucumbe à tentação de fazer uso da inteligência, em particular da agência de inteligência civil, mais orientada para questões internas, em detrimento de um enfoque estratégico e externo". ${ }^{50}$ Apesar de que o Comitê Associado de Supervisão de Segurança Interna e Atividades de Inteligência e Agências tinha, desde a sua criação em 1992, sido dotado de poderes formais sobre o acesso às pessoas e aos papéis dos serviços de inteligência, ele foi menos ativo nos anos 2000 do que era na década de 1990. ${ }^{51}$ Houve problemas contínuos com o controle da SI na Argentina, incluindo ministros que não forneciam documentos ou provas à comissão do Congresso. Em julho de 2003, um ex-ministro da justiça descreveu o SI como "um ministério paralelo secreto (...), que trabalha permanentemente em questões de segurança sem qualquer tipo de controle". ${ }^{52}$

No Brasil existe uma série de leis e regulamentações sobre a organização da inteligência. ${ }^{53}$ Mas Gonçalves observa que uma reforma séria no Brasil é dificultada não só pela ignorância dos políticos sobre o papel da inteligência, o que significa que ela recebe atenção insuficiente, mas, ainda mais, pela sua tendência em ver os serviços mais como "uma ameaça à democracia, do que como um setor do Governo, criado para aconselhar os que tomam decisões e para proteger o Estado e a sociedade". ${ }^{54} \mathrm{Na}$ mesma linha, Cepik conclui que a "eficácia geral no sistema brasileiro está melhorando porque o profissionalismo dessas pessoas que servem no sistema está avançando. A eficácia é, no entanto, dificultada pelo interesse relativamente baixo do estado no desenvolvimento da inteligência face a face outras questões de defesa". ${ }^{5}$

Especificamente, a ABIN ainda está lidando com o estigma do SNI, mas a ABIN é apenas uma das cerca de 20 agências federais com funções

48 CEPIK, Marco e BRUNEAU, Tom. Brazil, p.114.

49 ANTUNES, P. Argentina, p.100-106; e ESTÉVEZ, E. Argentina's intelligence in the twenty-first century, p.41-58.

50 ESTÉVEZ, E. Argentina's intelligence in the twenty-first century, p.89.

51 ESTÉVEZ, E. Argentina's intelligence in the twenty-first century, p.59.

52 Citado em: ANTUNES, P. Argentina, p.109. Ver também UGARTE, José Manuel. Latinoamérica, p.8.

53 Para a lista, ver: CEPIK, Marco e BRUNEAU, Tom. Brazil, p.117-121.

54 GONÇALVES, J. B. The spies who came from the tropics, p.2.

55 CEPIK, Marco. Structural change and democratic control of intelligence in Brazil. In: BRUNEAU, Thomas C. e BORAZ, Steven. Reforming intelligence, p.165. 
de inteligência no Brasil. ${ }^{56}$ O SISBIN só pode ser descrito como uma rede que, muitas vezes, só funciona por meio de conexões informais, em vez de formais. ${ }^{57}$ Embora a ABIN seja definida legalmente como a agência central (nodo), na prática, foi subordinada ao Gabinete de Segurança Institucional (GSI) do Presidente. Desde a virada do século, e mais enfatizado depois do 11 de setembro, o SISBIN foi reforçado por dois subsistemas de inteligência: um para a segurança pública (principalmente a polícia federal e estadual em relação ao crime, à ordem pública e ao terrorismo), o outro para inteligência de defesa. ${ }^{58}$

Em comparação a outros países, um elemento um tanto incomum no caso brasileiro é a papel abrangente do Ministério Público, que, numa posição-chave, deu início a vários processos contra os abusos cometidos pela (especialmente polícia) inteligência. ${ }^{59} \mathrm{Em}$ contraste com a Argentina, onde uma comissão de supervisão antecedia a Lei de Inteligência, levou quase um ano após a aprovação da lei antes que o Parlamento brasileiro criasse a Comissão Mista de Controle das Atividades de Inteligência do Congresso Nacional (CCAI), composta por três senadores e três membros da Câmara dos Deputados. A CCAl foi baseada no modelo dos EUA de supervisão e, então, seus poderes incluíam a supervisão potencial de operações. Mas, a ausência de ordens permanentes, recursos e vontade política (os políticos estavam muito ocupados em outros lugares) significou que ela teve apenas impacto simbólico. Ela dificilmente agiu além de responder a crises ocasionais. ${ }^{60}$

Uma dessas crises, em 2008, no entanto, provocou o Comitê a agir de forma mais efetiva. Sob o nome de Operação Satiagraha, houve interceptação ilegal de conversas telefônicas envolvendo políticos, ministros, banqueiros, funcionários públicos, advogados e juízes por parte da polícia e da ABIN. Por lei, a ABIN é proibida tanto de trabalhar com a polícia em investigações criminais, quanto de realizar interceptações. O inquérito subsequente do Congresso concluiu que centenas de milhares de interceptações irregulares haviam sido feitas pela polícia e o então presidente da CCAI, Severiano Alves, fez propostas radicais para estabelecer, por meio de uma emenda constitucional, o controle e a fiscalização da inteligência, bem como sugeriu a criação de um Conselho de Supervisão de Inteligência, como um corpo externo (moldado nos exemplos canadense e português). Mas a lei não passou e, assim, o desenvolvimento da reforma foi adiado novamente. ${ }^{61}$

56 GONÇALVES, J. B. The Spies who came from the tropics, p.4; CEPIK, Marco e BRUNEAU, Tom. Brazil, p.112, referem-se a "pelo menos 13". O problema de realmente identificar precisamente quantas agências de inteligência existem em um país não está restrito ao Brasil. A preocupação atual com a segurança interna ou da pátria viu uma proliferação de agências e unidades de segurança e inteligência dentro de outros departamentos em quase todos os lugares.

57 GONÇALVES, J. B. The spies who came from the tropics, p.8-11; CEPIK, Marco e BRUNEAU, Tom. Brazil, p.123.

58 CEPIK, Marco e BRUNEAU, Tom. Brazil, p.118-24.

59 GONÇALVES, J. B. The spies who came from the tropics, p.13-14

60 GONÇALVES, J. B. The spies who came from the tropics, p.15-16.

61 GONÇALVES, J. B. The spies who came from the tropics, p.16-22. 
A inteligência de Estado permanece potencialmente imune à fiscalização, em grande parte por causa da confidencialidade com que alguns de seus procedimentos são realizados. Assim, como Cepik e Ambros comentaram, mesmo a democratização não garante a não ocorrência de escândalos e crises, ${ }^{62}$ como demonstrou a Operação Satiagraha. Na Argentina, o debate sobre a Lei de Inteligência foi interrompido pela renúncia do vice-presidente Alvarez, acusado de comprar votos provavelmente com fundos não declarados da SIDE e, alguns anos mais tarde, em 2003, a espionagem política ordenada pelo ministro da inteligência, Sergio Acevedo, resultou na demissão de 160 pessoas da SI. ${ }^{63}$ Estévez relata escândalos contínuos sobre escutas telefônicas, mau uso do orçamento etc., durante os anos $2000 .{ }^{64}$

\section{Provedores de segurança das corporações}

Houve um crescimento geral e rápido da "inteligência" no setor privado, concomitante ao desenvolvimento de "indústrias do conhecimento" que se seguiu à revolução da informação e das comunicações ocorrida no último quarto de século. Para muitas corporações industriais e de serviço, a inteligência "competitiva" ou "de negócios" tem sido uma atividade de longa data, mas o setor privado está cada vez mais envolvido também na inteligência de "segurança", compensando os orçamentos decrescentes de segurança realizados pelo Estado durante os anos 1990, mas também refletindo a demanda crescente após o 11 de setembro, com a "venda" da ideia de uma permanente insegurança a ele relacionada. Durante todo esse tempo, informantes privados e fabricantes de segurança foram os principais desenvolvedores, fabricantes e fornecedores de informação, baseada em software de processamento de informações e hardware, junto com toda uma gama de serviços de guarda e vigia que constituem as atuais "sociedades de vigilância".

No entanto, esse crescimento representa um grande desafio às ideias de controle e fiscalização da inteligência em uma democracia. Agentes de segurança de corporações são organizações de maximização do lucro e, como tal, são dedicadas aos interesses particulares de clientes e acionistas que estão acima de qualquer noção mais ampla de "interesse público". Como vimos, a maioria dos países na América Latina sofreram no passado com as atividades dos "esquadrões da morte" público-privados e, portanto, deve haver uma preocupação real de que, como órgãos estatais encontram-se em graus mais elevados sob controle e submetidos a uma

62 CEPIK, Marco e AMBROS, Chris. Intelligence, crisis, and democracy: institutional punctuations in Brazil, Colombia, South Africa, and India. (no prelo)

63 ANTUNES, P. Argentina, p.99, 108.

64 ESTÉVEZ, E. Argentina's intelligence in the twenty-first century, p.69-74. 
maior transparência, tais esquadrões poderiam vir a proliferar. Portanto, não é de se estranhar que a Lei Argentina de Inteligência, de 2001, proíba o trabalho de inteligência desenvolvido por agências privadas. Mas a aprovação de uma lei é uma coisa, aplicá-la é outra: "fontes confiáveis estimam que existem cerca de 100.000 pessoas na vigilância privada e no setor de segurança na Argentina, a maioria dos quais são militares, policiais e agentes de inteligência que ainda estão ativos ou aposentados". ${ }^{65}$

Países democráticos, por todos os lugares, tiveram que lidar com a possibilidade real de persistência das agências de inteligência "paralelas", leais ao antigo regime e empregando antigos funcionários dos serviços de inteligência nos principais cargos corporativos, em sociedades recém-marketisadas. Dado que os acordos institucionais para controlar agências de inteligência do estado estão em um estágio inicial de desenvolvimento na América Latina, não é de se surpreender que a questão de controle dos agentes de segurança privada tem sido pouco contemplada. O Brasil, por exemplo, enfrenta o desafio atual de se preparar para sediar a Copa do Mundo de 2014 e os Jogos Olímpicos, no Rio, em 2016. Se a experiência de Londres na preparação para as Olimpíadas de 2012 é algo a ser seguida, então o Brasil terá que desenvolver uma rede de segurança e inteligência sem precedentes voltada para esses grandes eventos. Para Londres, a estimativa mais recente é de que a segurança local será fornecida por 12 mil policiais, até 13.500 militares e 10 mil pessoas de segurança privada, recrutados pelo G4S. ${ }^{66} \mathrm{O}$ problema enfrentado pelo Brasil, no entanto, é agravado pelo fato de que, em meados dos anos 2000 , apenas 30 mil dos 130 mil seguranças particulares no Rio são registrados e estima-se que cerca de $80 \%$ das empresas de segurança privada ilegais são controladas, se realmente não são possuídas, pelos policiais. ${ }^{67}$

\section{Provedores da "comunidade"}

Se a oferta de segurança pelas empresas particulares representa um problema para a democratização, então a fornecida pela "sociedade civil" ou pelas associações comunitárias é um problema ainda maior. Esses grupos assumem muitas formas, com diferentes graus de formalidade organizacional: movimentos de libertação nacional, grupos paramilitares, clãs, milícias tribais ou religiosas e organizações criminosas. O que esses "grupos", ou "soberanias" têm em comum é a vontade final de usar a violência para controlar as pessoas, recursos ou territórios. ${ }^{68}$ Enquanto em

65 ANTUNES, P. Argentina, p.106

66 Londres também recrutou 70.000 voluntários como guias, ajudantes, etc

67 GAY, Robert. Toward uncivil society: causes and consequences of violence in Rio de Janeiro. In: ARIAS, Enrique e GOLDSTEIN, Daniel. (eds.) Violent democracies in Latin America. Durham: Duke University Press, 2010, p.210-25.

68 WARNER, Michael. Intelligence as risk shifting. In: GILL, Peter et al. (eds.) Intelligence theory: key questions and debates. London: Routledge, 2009, p.16-32. As regras de negociação das Nações Unidas descrevem-os como grupos armados que não são do Estado, cujos motivações podem ser políticas, ideológicas ou econômicas. 
uma das extremidades de um amplo espectro isso é inteiramente legal e motivado por nada além do que espírito de comunidade, tais como os esquemas de "vigilância da vizinhança", que procuram dar apoio mútuo e informações relevantes para a polícia, na outra extremidade a "segurança" deteriora-se em vigilantismo, fornecido por alguns grupos nacionalistas ou redes criminosas não civis. Se os estados de transição são incapazes de atingir o monopólio de Weber de coerção legítima, eles continuam dependentes de atores não-estatais no que pode se tornar um pacto Faustiniano.

Como observa Adda Bozeman, mesmo antes da explosão pós Guerra Fria, quando então as ameaças passaram a ser assimétricas, o Estado "não era a unidade mais decisiva trabalhada nos estudos de inteligência". ${ }^{69}$ As redes criminosas mais organizadas podem desenvolver suas próprias redes de inteligência sofisticadas dentro da polícia, muitas vezes pela simples noção de "empregar" policiais corruptos, mas isso pode também envolver maior capacidade tecnológica. No que foi provavelmente um caso excepcional, por exemplo, um computador de grande porte que foi encontrado, em 1994, em um prédio de propriedade do cartel de Cali:

O cartel tinha construído um banco de dados que capturava os números de telefone dos escritórios e residências da polícia local, dos diplomatas americanos e dos agentes da DEA na Colômbia. Isto estava sendo combinado com todos os números de chamada locais, durante vários anos, cujos registros haviam sido comprados ilegalmente da companhia telefônica local. O computador estava implementando software de dados complexos, até então usado apenas pelos serviços de inteligência, que se concentravam em rastrear aqueles que ligavam repetidamente a um pessoal específico de segurança e inteligência. O cartel estava usando isso para caçar informantes. Oficiais colombianos concluíram que isso levou à morte de mais de doze vidas humanas. ${ }^{70}$

$\mathrm{Na}$ ausência da capacidade do Estado, grupos e organizações que constituem tais estruturas de poder podem muito bem oferecer um nível básico de segurança, que atinge certo grau de legitimidade entre a população local mesmo que, muitas vezes, em nome do controle da criminalidade e da ordem social elas imponham restrições maiores sobre direitos individuais e não sobre os Estados. Nas comunidades mais ricas, recursos poderiam ter sido destinados para a contratação de corporações de segurança privada, mas houve a preocupação em diversos países da região de que essas também podiam se degenerar em máfias e em grupos paramilitares e, de fato, algumas tentativas de policiamento comunitário na América Latina foram

NORWITZ, Jeffrey. Pirates, terrorists, and warlords: the history, influence, and future of armed groups around the world. New York: Skyhorse Publishing, 2009, p.457.

69 BOZEMAN, Adda. Political intelligence in non-western societies: suggestions for comparative research. In GODSON, Roy. (ed.) Comparing foreign intelligence. The US, the USSR, the UK, and the third world. Washington, D.C.: Pergamon-Brasseys, 1988, p.135.

70 ALDRICH, Richard. Beyond the vigilant state: globalisation and intelligence. Review of International Studies, v.35, n.3, p.889-902, 2009, p.895. 
por esse caminho. ${ }^{71}$ Martha Huggins, escrevendo sobre os esquadrões da morte no Brasil, concluiu: "Por fim, essa privatização da segurança interna, impulsionada no final das contas por interesses particulares, em vez de comuns e civis, institucionaliza uma cada vez mais privatizada e sub contratual resposta ao controle social que ao menos parece operar em paralelo ao sistema formal, mas é na verdade sincronizado com ele". ${ }^{72}$ Onde esse é o caso, a democratização deve ser definida não apenas em termos de controle democrático, mas também no desenvolvimento de capacidade suficiente do Estado em proporcionar segurança por meio da redução do poder das estruturas autônomas de poder. ${ }^{73}$ Esse é o problema político central colocado pelo "securitismo" como um modo de governança de segurança.

\section{Conclusão}

Há uma distinção fundamental entre a construção do Estado na Europa, onde os estados se desenvolveram através da guerra e da coerção, até que eles finalmente foram capazes de deslocar as elites latifundiárias para conseguir um monopólio quase weberiano do poder ${ }^{74}$ e o corporativismo na América Latina, onde "o Estado nunca aspirou exercer tal monopólio" e governa através de alianças indiretas com proprietários, fabricantes, chefes políticos e outros. ${ }^{75}$ Agora, a transição do regime autoritário tem sido acompanhada por uma diminuição da violência "política" do Estado com os cidadãos, em termos de violações graves dos direitos humanos, mas as pressões simultâneas do neoliberalismo aumentaram a desigualdade, que resulta em atividades criminosas principalmente relacionadas ao tráfico de drogas, aumentando a violência não estatal. Por sua vez, isso provocou novos incidentes de violência do Estado sob a forma de detenção arbitrária, tortura e assassinatos extrajudiciais. Tais respostas duras do estado são particularmente severas nos casos do México e do Brasil. ${ }^{76}$

No entanto, como sugerido pelo "securitismo", isso não é simplesmente um caso de aumento de violência do estado. Tem-se observado que os governos em muitas partes do mundo em desenvolvimento buscam reforçar sua posição política e compensar sua falta de capacidade trabalhando com os grupos armados, simplesmente ao invés de contra eles. ${ }^{77}$ Estévez

71 ARIAS, Enrique e GOLDSTEIN, Daniel. Violent pluralism: understanding the new democracies of Latin America. In: ARIAS, Enrique e GOLDSTEIN, Daniel (eds.). Violent democracies in Latin America, p.1-34; DIAMINT, R. Military, police, politics, and society, p.164-65.

72 HUGGINS, Martha K. Modernity and devolution: the making of police death squads in Brazil. In: CAMPBELL, B. e BRENNER, A. (eds) Death squads in global perspective. Houndmills: Macmillan, 2000, p.211-212.

73 Cf. TILLY, Charles. Democracy, p.137.

74 Cf. TILLY, Charles. War making and state making as organized crime. In: EVANS, Peter et al. (eds.) Bringing the state back in. Cambridge: Cambridge UP, 1985.

75 PEARCE, Jenny. Perverse state formation and securitized democracy in Latin America. Democratization, v.17, n.2, p.286-306, 2010.

76 LANDMAN, Todd. Violence, democracy and human rights in Latin America. In: ARIAS, Enrique e GOLDSTEIN, Daniel. (eds.) Violent democracies in Latin America, p 226-241.

77 Cf. ARIAS, Enrique e GOLDSTEIN, Daniel. Violent pluralism, p.9 
refere-se à continuidade da atividade de estruturas paralelas de inteligência no final dos anos 80 na Argentina. ${ }^{78}$

Algumas coisas podem ter mudado nos últimos anos, mas enquanto os extremos de desigualdade coexistirem com a corrupção policial e a baixa capacidade de ação do estado, então estará presente um potencial contínuo de patrocínio, fraude ou cegueira da polícia para a persistência das atividades paramilitares. Por exemplo, a análise da organização do tráfico de drogas na América Latina mostra que, embora existam diferenças em toda a região, são as redes criminosas que reúnem agentes tanto do estado quanto da sociedade civil e que os criminosos procuram manter o apoio contribuindo para as organizações e as comunidades civis. ${ }^{79} \mathrm{O}$ desempenho desse tipo de funções "semelhantes aos do estado", é claro, reforça a imagem do "securitismo" como caracterizado por uma complexa interpenetração dos estados, das corporações e das organizações na "comunidade". É por isso que argumenta-se que o contexto da SSR para o estudo da reforma da inteligência é mais útil do que o foco estreito das relações civis-militares.

Muito precisa ser feito na pesquisa da interface da inteligência e da democracia, especialmente no contexto da consolidação da democracia em meio a altos níveis de violência e crime. Como observa Estévez, a restauração da democracia não é uma condição suficiente por si só para a reforma dos serviços de inteligência, ${ }^{80}$ especialmente porque os governos estão ansiosos para serem vistos como fornecedores de "segurança" ou, pelo menos, serem capazes de aparentar isso, e os agentes de inteligência e de segurança estão bem posicionados nesse particular para permanecerem como um "enclave autoritário". ${ }^{81}$ Essa possibilidade foi reforçada desde o 11 de setembro, porque o que tinha sido visto como a distinção necessária entre segurança interna e externa, que os reformadores da América Latina haviam procurado estabelecer, a fim de controlar o papel dos militares, foi quase obliterado pela retórica posterior e pelas práticas de segurança. Isso tornou mais fácil para que os militares justificassem qualquer retomada sobre as funções de segurança interna. ${ }^{82}$ Whitehead argumenta que a "democradura", após o 11 de setembro, pode ter se tornado o "único jogo na cidade", em Washington, mas que isso não iria repercutir fortemente na América Latina porque lá o "terrorismo" não é visto como uma ameaça significativa em comparação com questões mais fundamentais de insegurança econômica. ${ }^{83}$ Esse pode muito bem ser o caso, mas as pressões

78 ESTÉVEZ, E. Argentina's intelligence in the twenty-first century, p.28.

79 ARIAS, Enrique. Drugs and democracy in Rio de Janeiro. Chapel Hill: University of North Carolina Press, 2006, p.187-88.

80 ESTÉVEZ, E. Comparing intelligence democratization in Latin America

81 DIAMOND, L. Developing democracy, p.133-34.

82 Cf. DIAMINT, R. Military, Police, politics, and society, p.168

83 WHITEHEAD, Laurence. The fading regional consensus. In: DOMINGUEZ, Jorge e SHIFTER, Michael. (eds.) Constructing democratic governance in Latin America, p.13-38. 
institucionais de agências, empresas e aliados da "comunidade" podem ser tais que a maioria das pessoas permaneçam excluídas de um "securitismo", que mantém instintos autoritários significativos em um contexto de violência social generalizada. Esse deve ser o foco central para a pesquisa em governança de inteligência atual. 